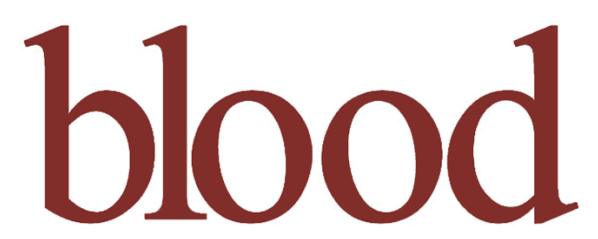

2010 115: 2146-2155

Prepublished online January 21, 2010;

doi:10.1182/blood-2009-09-241869

\title{
$B$ cell-specific lentiviral gene therapy leads to sustained B-cell functional recovery in a murine model of $X$-linked agammaglobulinemia
}

Hannah M. Kerns, Byoung Y. Ryu, Brigid V. Stirling, Blythe D. Sather, Alexander Astrakhan, Stephanie Humblet-Baron, Denny Liggitt and David J. Rawlings

Updated information and services can be found at: http://bloodjournal.hematologylibrary.org/content/115/11/2146.full.html

Articles on similar topics can be found in the following Blood collections

Gene Therapy (495 articles)

Hematopoiesis and Stem Cells (2964 articles)

Immunobiology (4699 articles)

Information about reproducing this article in parts or in its entirety may be found online at:

http://bloodjournal.hematologylibrary.org/site/misc/rights.xhtml\#repub_requests

Information about ordering reprints may be found online at:

http://bloodjournal.hematologylibrary.org/site/misc/rights.xhtml\#reprints

Information about subscriptions and ASH membership may be found online at:

http://bloodjournal.hematologylibrary.org/site/subscriptions/index.xhtml

Blood (print ISSN 0006-4971, online ISSN 1528-0020), is published weekly by the American Society of Hematology, 2021 L St, NW, Suite 900,

Washington DC 20036.

Copyright 2011 by The American Society of Hematology; all rights reserved.

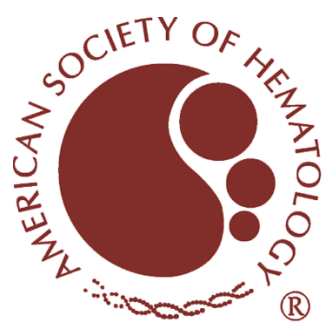




\title{
B cell-specific lentiviral gene therapy leads to sustained B-cell functional recovery in a murine model of X-linked agammaglobulinemia
}

\author{
Hannah M. Kerns, ${ }^{1}$ Byoung Y. Ryu, ${ }^{1}$ Brigid V. Stirling, ${ }^{1}$ Blythe D. Sather, ${ }^{1}$ Alexander Astrakhan, ${ }^{2}$ Stephanie Humblet-Baron, ${ }^{3}$ \\ Denny Liggitt, ${ }^{4}$ and David J. Rawlings ${ }^{1,2,5}$ \\ ${ }^{1}$ Center for Immunity and Immunotherapies, Seattle Children's Research Institute, WA; 2Department of Immunology, University of Washington School of \\ Medicine, Seattle; ${ }^{3}$ Center for Cellular and Molecular Therapy, GIGA-R, University of Liège, Liège, Belgium; and Departments of ${ }^{4}$ Comparative Medicine and \\ ${ }^{5}$ Pediatrics, University of Washington School of Medicine, Seattle
}

\begin{abstract}
The immunodeficiency disorder, X-linked agammaglobulinemia (XLA), results from mutations in the gene encoding Bruton tyrosine kinase (Btk). Btk is required for pre-B cell clonal expansion and $B-c e l l$ antigen receptor signaling. XLA patients lack mature $B$ cells and immunoglobulin and experience recurrent bacterial infections only partially mitigated by life-long antibody replacement therapy. In pursuit of definitive therapy for XLA, we tested ex vivo gene therapy using a lentiviral vector (LV)
\end{abstract}

containing the immunoglobulin enhancer $(E \mu)$ and $\lg \beta$ (B29) minimal promoter to drive $B$ lineage-specific human Btk expression in Btk/Tec ${ }^{-l-}$ mice, a strain that reproduces the features of human XLA. After transplantation of E $\mu$ B29-Btk-LV-transduced stem cells, treated mice showed significant, albeit incomplete, rescue of mature $B$ cells in the bone marrow, peripheral blood, spleen, and peritoneal cavity, and improved responses to T-independent and T-dependent antigens. LV-treated B cells exhibited enhanced B-cell antigen receptor signaling and an in vivo selective advantage in the peripheral versus central B-cell compartment. Secondary transplantation showed sustained Btk expression, viral integration, and partial functional responses, consistent with long-term stem cell marking; and serial transplantation revealed no evidence for cellular or systemic toxicity. These findings strongly support pursuit of B lineage-targeted LV gene therapy in human XLA. (Blood. 2010;115:2146-2155)

\section{Introduction}

The primary humoral immunodeficiency, X-linked agammaglobulinemia (XLA), is characterized by a block in early B-cell development leading to a severe reduction in generation, activation, and survival of mature B-lineage cells. ${ }^{1,2}$ Antibody responses and circulating immunoglobulin levels are profoundly decreased, and affected males develop life-threatening bacterial infections. Current therapy consists of chronic administration of intravenous immunoglobulin and antibiotics. This is only partially effective, expensive, and associated with several long-term complications.

The related immunodeficiencies, XLA and murine X-linked immunodeficiency (XID), result from deficient function of the nonreceptor tyrosine kinase, Bruton tyrosine kinase (Btk). Btk is expressed at all stages of B-lineage development, from pro-B to mature B cells, and is down-regulated in plasma B cells. ${ }^{3}$ Btk is also expressed in erythroid precursors, myeloid cells, mast cells, and megakaryocytes, but absent in $\mathrm{T}$ and NK lineages. Btk is required for pre-B-cell expansion and mature B-cell survival and activation via signals initiated by pre-B-cell antigen receptors (pre-BCRs) and B-cell antigen receptors (BCRs), respectively.

There is a strong selective advantage for B-lineage cells expressing a normal Btk gene. XLA carrier females and female $\mathrm{Btk}^{+/-}$mice exhibit nonrandom $\mathrm{X}$-inactivation in both bone marrow (BM) and peripheral B-lineage populations. ${ }^{4,5}$ Transplantation of normal BM or fetal liver cells can rescue immune responses in XID mice without marrow conditioning. ${ }^{6,7}$ Serum immunoglobulin levels and T-independent type 2 (TI-II) immune responses can

Submitted September 3, 2009; accepted December 28, 2009. Prepublished online as Blood First Edition paper, January 21, 2010; DOI 10.1182/blood2009-09-241869.

The online version of this article contains a data supplement. be restored in sublethally irradiated animals with as few as $2.5 \times 10^{4}$ donor cells and reconstitution of less than $10 \%$ WT cells in the spleen. ${ }^{8}$ These observations have suggested that introduction of the normal BTK cDNA into autologous hematopoietic stem cells (HSCs) might lead to immunologic reconstitution, an improved quality of life, and increased life expectancy in XLA. In support of this idea, we previously demonstrated rescue of Btk-dependent B-cell development and function in Btk-deficient mice using a recombinant gammaretroviral vector (RV) expressing human Btk. ${ }^{9}$

Notably, recent work has shown that RV-based HSC gene therapy can provide significant clinical benefits in patients with severe combined immune deficiency (SCID). ${ }^{10,11}$ Unfortunately, RV therapy in both X-linked SCID and chronic granulomatous disease has led to unanticipated adverse events because of LTRmediated, proto-oncogene transcriptional activation. ${ }^{12,13}$ Thus, activating RV insertions can lead to emergence of clonal dominance, as well as clonal fluctuation, which may also eliminate or reduce ongoing clinical benefit.

These events have focused attention on self-inactivating (SIN) lentiviral vectors (LVs) as potential alternative delivery platforms for hematopoietic disorders. LVs offer the advantage of targeting nondividing cells and can efficiently target multipotent, nonhuman primate or human HSCs at low viral copy number. ${ }^{14,15}$ LVs also limit the risk of viral LTR enhancer mutagenesis and permit the use of lineage-specific expression cassettes. ${ }^{16}$ Further, there is less evidence for transcriptional silencing of internal promoters within 
integrated LV and no bias for integration within transcription start sites. ${ }^{17,18}$ These combined features probably reduce the overall risk of LV-mediated mutagenesis.

Following up on our initial success with RV Btk gene therapy, we developed a novel LV optimized for expression in B cells. Transplantation of transduced, lineage-negative (lin ${ }^{-}$), HSCs into myeloablated Btk/Tec double-knockout $\left(\mathrm{Btk} / \mathrm{Tec}^{-/-}\right.$) recipients led to progressive rescue of central and peripheral Btk-dependent, B-lineage development, and improved TI-II immune responses and proliferation in response to B-cell mitogens. Mature B cells derived from Btk-transduced stem cells exhibited a progressive selective advantage, and BM derived from primary recipients also partially rescued B-cell development and function in secondary transplanted hosts, without evidence for acute or long-term toxicity.

\section{Methods}

More detailed methodology is provided in supplemental data (available on the Blood website; see the Supplemental Materials link at the top of the online article).

\section{LV constructs and viral production}

The $\mathrm{E} \mu \mathrm{B} 29$ promoter/enhancer was generated by combining the murine immunoglobulin heavy chain enhancer with $5^{\prime}$ and $3^{\prime}$ MAR elements ${ }^{19,20}$ $(\mathrm{E} \mu)$ in association with a minimal promoter element derived from the $B 29$ gene (184-bp of the murine promoter, including -166 to +18 from the major transcriptional start site). ${ }^{21}$ The LV, pRRL-E $\mu$ B29-Btk, was generated by replacing phosphoglycerate kinase-green fluorescent protein (PGKGFP) sequences from pRRL-SIN-cppt-PGK-GFP-WPRE ${ }^{22}$ with E $\mu$ B29, and a full-length human $B T K$ cDNA. pRRL-E $\mu B 29-B$ tk-2A-GFP was generated by insertion of a self-cleaving $2 \mathrm{~A}-\mathrm{GFP}$ sequence in frame with $B T K$ cDNA. LVs were produced by transient transfection of $293 \mathrm{~T}$ cells using standard $\mathrm{CaPO}_{4}$ methods and concentrated by low-speed centrifugation. Viral titers were determined by real-time quantitative polymerase chain reaction (PCR).

\section{Stem cell transduction and transplantation}

Control C57BL/6 mice (The Jackson Laboratory) and Btk/Tec ${ }^{-1-}$ mice $^{23}$ were maintained in the specific pathogen-free barrier facilities at Seattle Children's Research Institute. Animal studies were carried out with the approval of Seattle Children's Research Institute Institutional Animal Care and Use Committee. BM harvested from 6- to 16-week-old mice was subject to magnetic bead lineage depletion (StemCell Technologies), and isolated $\mathrm{Lin}^{-} \mathrm{BM}$ cells were transduced overnight in media (StemSpan SFEM; StemCell Technologies) containing mSCF and mTPO $(10 \mu \mathrm{g} / \mathrm{mL}$; PeproTech), with or without concentrated E $\mu$ B29-Btk-LV at indicated multiplicity of infection (MOI). After transduction, lethally irradiated $(900-1100 \mathrm{cGy}) \mathrm{Btk} / \mathrm{Tec}^{-1-}$ mice were transplanted with approximately $1 \times 10^{6} \mathrm{Lin}^{-} \mathrm{BM}$ cells. For secondary transplantation, total BM (5$\left.10 \times 10^{6}\right)$ derived from primary recipients was injected into cohorts $(2$ or 3 secondary recipients/donor) of lethally irradiated $\mathrm{Btk} / \mathrm{Tec}^{-1-}$ mice. Transplanted mice were evaluated by serial peripheral blood analyses beginning at 5 weeks, immunization with T-independent (TNP-Ficoll) or T-dependent (NP-CGG) antigens beginning at approximately 15 weeks, and cohorts were killed at 24 to 26 weeks for complete developmental and functional analysis.

\section{Flow cytometry}

Single-cell suspensions prepared from BM, spleen, PB, and peritoneal washes were incubated with fluorochrome-conjugated antibodies for $30 \mathrm{~min}$ utes at $4^{\circ} \mathrm{C}$ (see supplemental data for list of antibodies used). Cytofix/ Cytoperm and Alexa 647-conjugated anti-human Btk (53/BTK) were used for intracellular Btk staining (BD Biosciences PharMingen). Cell analysis was performed using FACSCalibur and LSRII flow cytometers (BD
Biosciences) and FlowJo software (TreeStar). Total cell numbers were determined for BM, spleen, and peritoneal cavity by multiplying subset percentages (expressed as percentage of live cells) by total tissue cell counts.

\section{Immunizations}

For T cell-independent immunization, mice were injected intraperitoneally with $10 \mu \mathrm{g}$ of TNP-Ficoll (Biosearch Technologies) and sera collected at days 10 to 14 after immunization. Total $\operatorname{IgM}$, total $\operatorname{IgG}_{3}$, TNP-IgM, and TNP- $\operatorname{IgG}_{3}$ were evaluated using enzyme-linked immunosorbent assays (ELISAs), as described previously. ${ }^{9}$ For T cell-dependent immunization, a subset of mice that did not see TNP-Ficoll were injected intraperitoneally with $100 \mu \mathrm{g}$ of NP-CGG in $100 \mu \mathrm{L}$ of alum and sera collected at days 0,7 , and 14 after immunization. NP-IgM was evaluated at days 0 and 7, and NP-IgG was evaluated at days 0 and 14 .

\section{Viral copy number determination}

Quantification of viral integration was adapted from a previously described protocol. ${ }^{9}$ Briefly, genomic DNA (gDNA) was obtained from total BM, spleen, or magnetically separated $\mathrm{CD} 43^{+}$and $\mathrm{CD} 43^{-}$splenocytes (Miltenyi Biotec). Gag-specific primer/probe sets (see supplemental data for sequences) were used to amplify viral integrations, and a murine $\beta$-actin primer/probe set was used to normalize DNA content. Viral integration number was determined via a standard curve established using gDNA extracted from A20 murine B-cell line containing a single LV integration.

\section{Calcium flux, cell proliferation, and colony-forming unit cell assays}

Calcium flux measurements were performed as previously described ${ }^{24}$ after loading of cell lines or splenocytes with AM Ester Indo-1 (Invitrogen). Splenocytes from treated mice were cultured with mitogens, loaded with ${ }^{3} \mathrm{H}$-thymidine, and analyzed for proliferation; splenocytes or BM colonyforming units were determined as previously described. ${ }^{9}$

\section{Immunohistochemistry}

Frozen sections $(6 \mu \mathrm{m})$ were obtained from mouse spleens embedded in OCT medium (Sakura). After fixation and blocking, slides were stained at room temperature for 30 minutes with biotin-conjugated anti-MOMA-1 (BMA Biomedicals), Alexa 647-conjugated anti-IgM (Invitrogen), and fluorescein isothiocyanate-conjugated anti-IgD (BD Biosciences); and then stained with Alexa 568-conjugated streptavidin (Invitrogen) and photographed with identical settings for all images using a Leica DM6000B microscope with an HCX PL Fluotar $10 \times / 0.30$ NA objective (original magnification, 100×), a Leica DFC360FX monochrome camera, and LAS AF6000E software (Leica Microsystems). No imaging medium was used. Brightness and contrast were adjusted identically using Adobe Photoshop Version 10.

\section{Statistical analysis}

Statistical analyses of relative Btk marking and viral copy numbers were carried out using a 2-tailed paired Student $t$ test comparing the indicated experimental cell populations. All other statistical measurements were carried out using a 2-tailed unpaired Student $t$ test to compare data from LV versus mock-treated $\mathrm{Btk} / \mathrm{Tec}^{-1-}$ recipients.

\section{Results}

\section{Design and in vitro testing of a novel B lineage-specific Btk-LV}

To avoid the potential risks associated with ubiquitous LTR promoter-driven Btk expression, we initiated studies using a novel SIN LV containing a B lineage-specific internal promoter/ enhancer. We used an LV vector, RRL-E $\mu$ B29-Btk (E $\mu$ B29-Btk; Figure 1A), containing a minimal promoter derived from the $B 29$ 
A

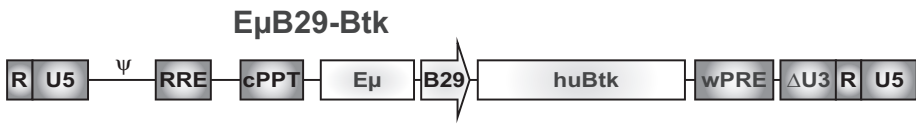

B

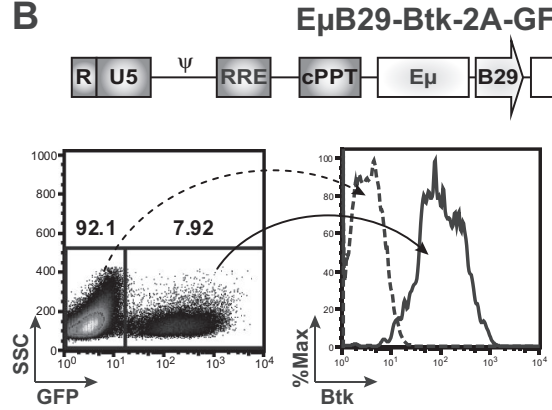

EHB29-Btk-2A-GFP (Btk-GFP) huBtk $2 \mathrm{2A}$

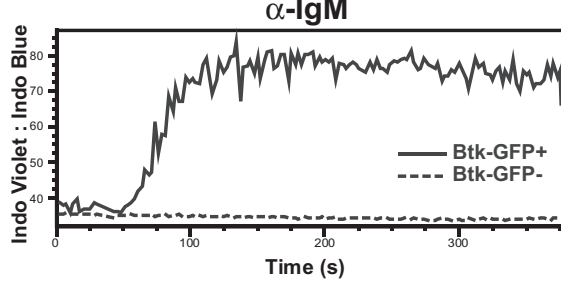

Figure 1. $E_{\mu} B 29-B t k-L V$ restores calcium flux in Btk-deficient B cells. (A) Schematic of the LV E $\mu$ B29Btk used for all murine transplantation experiments. Expression of the human BTK CDNA transgene is driven by a $B 29(\lg \beta)$ minimal promoter in conjunction with an Ig heavy chain enhancer $(E \mu)$. (B) Schematic of $E_{\mu} B 29-B t k-$ 2A-GFP (Btk-GFP) vector used in DT40 transduction experiments. Btk-deficient DT40 chicken B cells were transduced at limiting MOI and evaluated for GFP and Btk expression by FACS (left panels). Transduced cells were stimulated with anti-IgM and analyzed for calcium flux within the $\mathrm{GFP}^{+}$vs GFP ${ }^{-}$fractions (right panel). gene (also known as $\operatorname{Ig} \beta, \mathrm{CD} 79 \mathrm{~b}$ ) in conjunction with the immunoglobulin heavy chain intronic enhancer, $\mathrm{E} \mu$, to drive expression of a human BTK cDNA. B29 is a key signaling component of the BCR, expressed in a pattern nearly identical to Btk. Extensive analyses using a related LV containing only a GFP marker gene demonstrated that the E $\mu$ B29 promoter/enhancer mediates high-level, B lineage-restricted expression in murine and human, BM- and splenic-derived, primary B-cell subsets (B.D.S. and D.J.R., manuscript submitted).

The capacity of E $\mu$ B29-Btk to restore Btk function was initially tested in an avian B lymphoma cell line, Btk ${ }^{-1-}$ DT-40. ${ }^{25}$ Cells were transduced with E $\mu$ B29-Btk-2A-GFP (Figure 1B) at low MOI to bias for populations with low viral copy number (GFP marking $<10 \%$; Figure 1B left panel), and Btk marking was confirmed by intracellular flow cytometry (Figure 1B middle panel). Btk functions as a highly specific phospholipase $\mathrm{C}$ kinase and a scaffold, concurrently regulating phospholipase $\mathrm{C} \gamma 2$ activity by site-specific phosphorylation and by facilitating its access to its enzymatic substrate. ${ }^{26}$ Through these activities, Btk controls the sustained calcium signal triggered in response to either pre-BCR or BCR engagement. As shown in Figure 1B (right panel), the Btk expressing $\left(\mathrm{GFP}^{+}\right)$subset exhibited rescue of $\mathrm{BCR}$-triggered, Btk-dependent calcium signal, whereas the $\mathrm{Btk}^{\text {null }} / \mathrm{GFP}^{-}$population failed to respond. In contrast, both populations responded to control ionomycin stimulation (data not shown).

Next, we generated a series of E $\mu$ B29-Btk-transduced, Btk ${ }^{-/-}$ DT-40 B-cell clones by limiting dilution to assess functional recovery in single viral integrant clones (demonstrated by Southern blotting; not shown). Btk expression was confirmed using FACS and Western blotting, and rescue of the Btk-dependent calcium signal was observed in multiple independent B-cell clones (supplemental Figure 1). In addition, E $\mu$ B29-Btk rescued the calcium signal in LV-transduced, sIgM ${ }^{+} \mathrm{LMP}^{-}$EBV B-cell lines derived from XLA patients ${ }^{27}$ (data not shown), showing functional activity in Btk-deficient mammalian as well as in avian B cells.

\section{$\mathrm{E} \mu \mathrm{B} 29-\mathrm{Btk}$ restores $\mathrm{BM}$ and peripheral B-cell development in Btk/Tec ${ }^{-I-}$ mice}

Based on these findings, we initiated studies of E $\mu$ B29-Btk gene therapy using Btk/ $/ \mathrm{Tec}^{-1-}$ mice, a strain that accurately mimics the B-cell developmental and functional phenotype of human XLA. ${ }^{23}$ Lin $^{-}$BM cells were transduced (MOI 3-100) and transplanted into lethally irradiated recipients. As positive and negative controls, respectively, additional cohorts of $\mathrm{Btk} / \mathrm{Tec}^{-/-}$recipients were transplanted with $\mathrm{Lin}^{-} \mathrm{BM}$ derived from either C57/B16 wild-type
(WT mock) or Btk/ $\mathrm{Tec}^{-/-}$(KO mock) mice, cultured under identical conditions in the absence of LV.

$\mathrm{Btk} / \mathrm{Tec}^{-1-}$ mice exhibit decreased total and mature B-cell numbers in the $\mathrm{BM}, \mathrm{PB}$, spleen, and peritoneal cavity. As shown in Figure 2A, within 16 to 19 weeks after transplantation, analysis of $\mathrm{PB}$ revealed a marked increase in both total and Hardy fraction I $\left(\mathrm{IgM}^{\mathrm{lo}} \mathrm{IgD} \mathrm{D}^{\mathrm{hi}}\right)$ mature $\mathrm{B}$ cells in recipients of $\mathrm{E} \mu \mathrm{B} 29-\mathrm{Btk}$-transduced, Lin $^{-}$HSCs: MOI 15 to $25(30.7 \% \pm 13.8 \%$ total B and $20.9 \% \pm 5.3 \%$ fraction I, respectively) and MOI 50 to 100 $(26.8 \% \pm 8.3 \%$ and $23.4 \% \pm 6.0 \%)$, compared with $\mathrm{KO}$ mock $(11.5 \% \pm 5.7 \%$ and $5.6 \% \pm 1.3 \%)$. Only a modest increase in PB B-cell numbers was observed using MOI $3(20.1 \% \pm 10.1 \%$ and $12.6 \% \pm 9.2 \%$ ). LV MOI 3 was insufficient to significantly reverse these cellular deficits. In contrast, MOI 15 to 100 consistently restored B-cell numbers, and similar rescue was observed using "medium" (15-25) versus "high" (50-100) MOI (4 independent experiments).

To evaluate the capacity to reconstitute the B-cell lineage in greater detail, recipient animals were killed at 24 to 26 weeks after transplantation. Cells were isolated from BM, spleen, and peritoneal cavity, and absolute numbers and the relative percentage of each B-cell subset were assessed using flow cytometry (Figure 2B-D and supplemental Figure 2A-C, respectively). Within the BM, LV- and mock-treated controls exhibited similar numbers of pro/pre-B cells (Figure 2B). In contrast, mice at MOI 15 to 25 and MOI 50 to 100 showed significant increases in the percentage and number of immature and recirculating $\mathrm{B}$ cells compared with $\mathrm{KO}$ mock controls. Interestingly, LVtreated mice had larger numbers of immature B cells compared with WT controls, perhaps because of reduced competition for niche space with mature recirculating B cells, present in somewhat lower numbers in LV-treated mice.

In the spleen, E $\mu$ B29-Btk-treated mice exhibited a significant increase in total $B$ cells. This reflected an increase in each of the major splenic B-cell subsets, including transitional (T1/T2), marginal zone (MZ)/MZ progenitors, and follicular mature (FM; Figure 2C); and of progressively more mature Hardy fraction II (Fr II) and I (Fr I) B cells (Figure 2D). Although significantly increased, the absolute number of FM $\mathrm{B}$ cells remained below that in WT mock recipients, and LV-treated animals also exhibited greater variability in FM cell numbers. Thus, LV gene transfer rescued the key mature populations, FM and MZ B cells, required for adaptive and innate B-cell immune responses, respectively. 
A
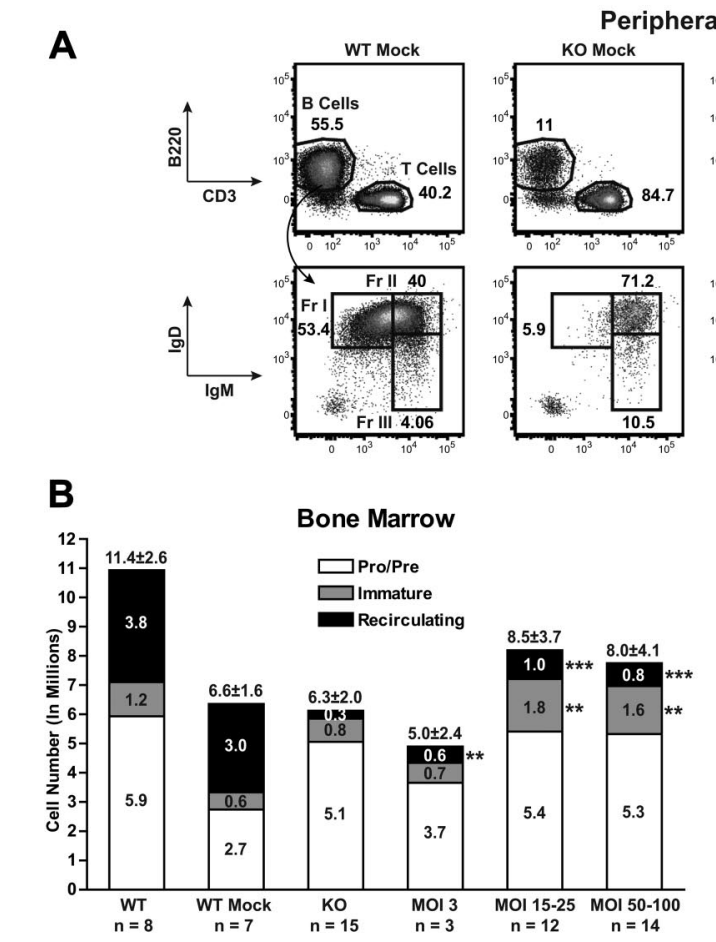

Peripheral Blood
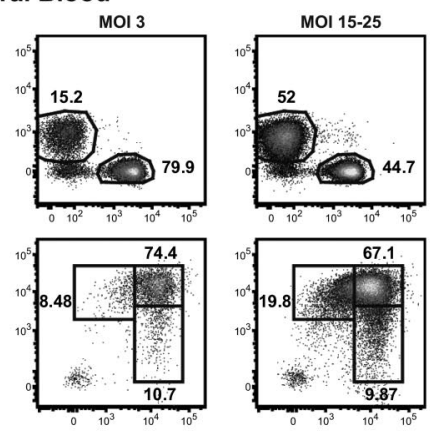

C
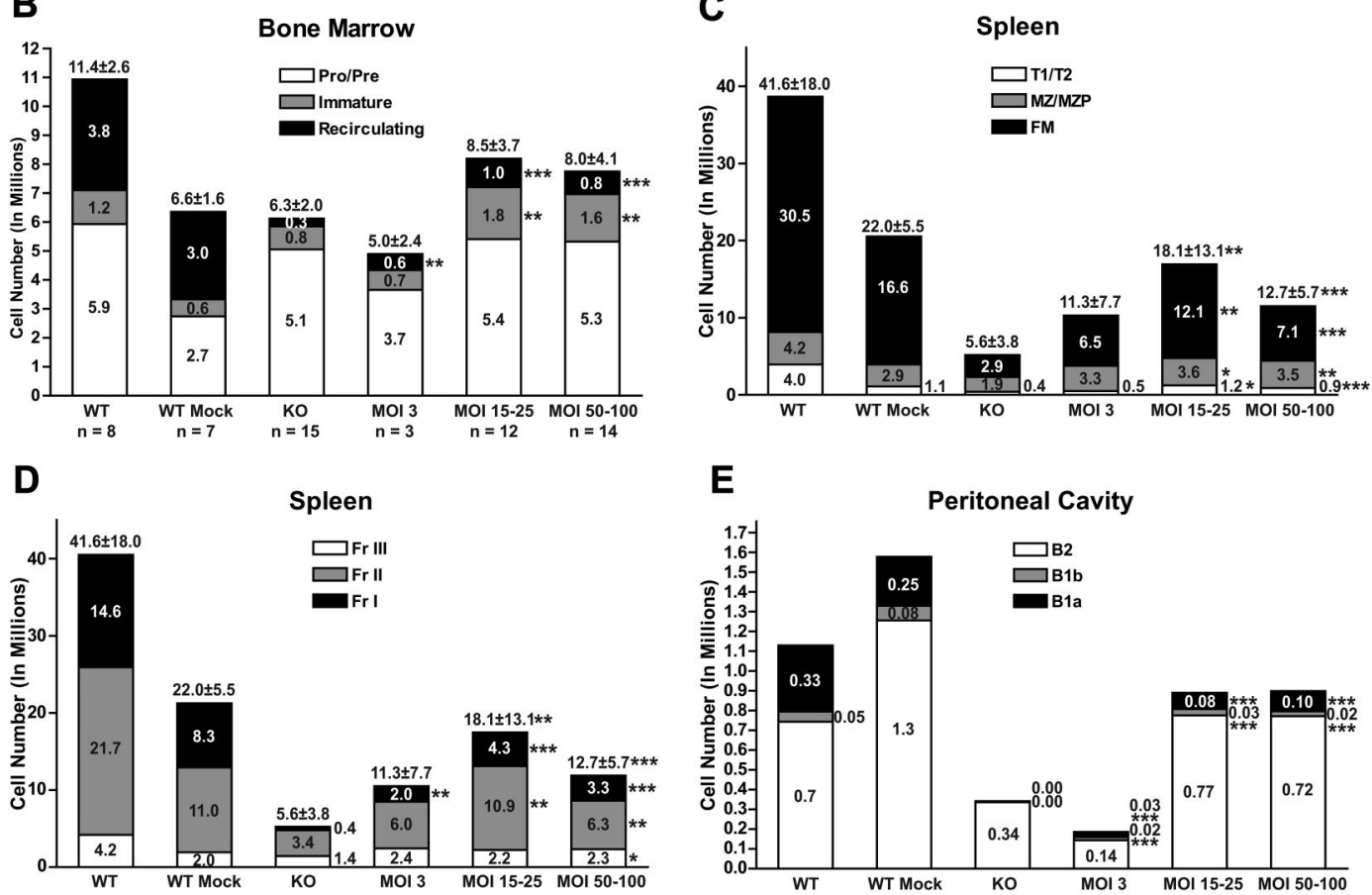

Figure 2. E $\mu$ B29-Btk gene therapy restores central and peripheral B-cell development. PB, BM, spleen, and peritoneal cells from LV-treated mice and mock controls were stained for surface markers and analyzed by flow cytometry to identify B-cell subsets (supplemental Figure 2, gating strategy). (A) PB cells were first gated on live and CD11bpopulations and then analyzed for B220, IgM, and IgD expression. FACS plots show representative mice from WT mock $(n=7), \mathrm{KO}$ mock $(n=8)$, MOI $3(n=3)$, and MOI 15 to $25(n=12)$ experimental groups. (B-E) Total cell numbers in each B-cell subset were determined for BM, spleen, and peritoneal cavity. In bar graphs, KO data include both unmanipulated and mock-transplanted animals. Data represent 4 independent experiments. $P$ values compare $\mathrm{E} \mu \mathrm{B} 29-\mathrm{Btk}$ and $\mathrm{KO}$ groups: ${ }^{\star \star \star} P<.001 ;{ }^{\star \star} P=.001-.01$; ${ }^{*} P=.01-05$.

$\mathrm{Btk} / \mathrm{Tec}^{-/-}$mice fail to generate peritoneal B1 B cells, essential for rapid, innate-like responses to serosal or bloodborne infection with encapsulated bacteria. ${ }^{28}$ Within the B1 population, $\mathrm{CD}^{+} \mathrm{B} 1$ a cells compose a specialized, more mature (probably antigen experienced) population distinct from CD5 ${ }^{-}$ B1b cells. E $\mu$ B29-Btk-treated mice exhibited a significant increase in both B1 subsets, with the greatest increase in B1a B cells at MOI 15 to 25 and 50 to 100 .

$\mathrm{Btk} / \mathrm{Tec}^{-/-}$mice also show structural abnormalities within the lymphocyte compartments of the spleen, with few or no discernable splenic follicles, a disrupted marginal zone, and poor B- and T-cell segregation. ${ }^{23}$ To evaluate these parameters, we performed immunohistochemistry on spleen sections from secondary transplantation mice (Figure 3). Compared with WT controls, WT mock animals exhibited somewhat less well-developed follicles, presumably because of the impact of lethal irradiation. Spleens from KO mock recipients (or unmanipulated $\mathrm{KO}$ controls; not shown) exhibited relatively small clusters of $\operatorname{IgM}^{+} \mathrm{B}$ cells, with partially disrupted follicular structures lacking a distinct $\mathrm{MOMA}^{+}$marginal zone (Figure 3A-D). In contrast, spleens from mice receiving MOI 15 to $25 \mathrm{BM}$ exhibited follicles similar in number and size to WT mock controls, containing both $\mathrm{IgM}^{+}$and $\mathrm{IgD}^{+} \mathrm{B}$ cells and a well-demarcated $\mathrm{MOMA}^{+}$border ringed by $\operatorname{IgM}^{+} \mathrm{MZ}$ B cells (Figure 3E-F).

\section{E $\mu$ B29-Btk-expressing B cells demonstrate a strong selective advantage}

Over the course of each E $\mu$ B29-Btk gene transfer experiment, we observed a progressive increase in the relative percentage of $\mathrm{Btk}^{+}$ PB B cells. In the representative experiment shown (Figure 4A), $\mathrm{Btk}^{+} \mathrm{B}$ cells increased approximately 2- to 3-fold between weeks 5 and 24 at MOI 3 and MOI 15 to 25; and these Btk ${ }^{+}$cells exhibited a mean fluorescent intensity equivalent to WT B cells. In contrast, although a small percentage of $\mathrm{Btk}^{+}$myeloid cells were consistently observed in LV-treated mice (reflecting partial myeloid lineage promoter/enhancer activity; data not shown), this marking level did not increase over time. Consistent with lack of selection 

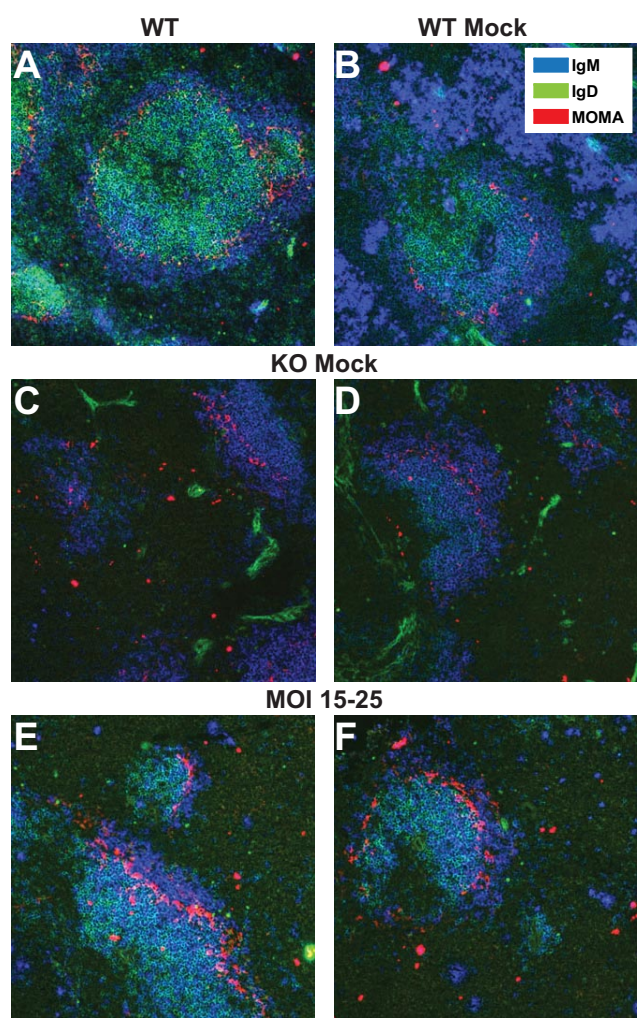

Figure 3. $\mathrm{E}_{\mu} \mathrm{B} 29-\mathrm{Btk}-\mathrm{LV}$ therapy restores splenic follicular morphology. Frozen sections from secondary transplantation mice were stained for IgM (blue), IgD (green), and MOMA (red) and then imaged using fluorescence microscopy. Slides were analyzed for the presence of follicles, indicated by $\mathrm{lgM}^{\mathrm{lo}} \mathrm{lg} \mathrm{D}^{\text {hi }}$ follicular $\mathrm{B}$ cells (green) separated from lgM $\mathrm{M}^{\text {hilgD }} \mathrm{D}^{\mathrm{o}}$ marginal zone $\mathrm{B}$ cells (blue) by a ring of $\mathrm{MOMA}^{+}$ marginal zone macrophages (red). Images show representative spleen sections from a WT control mouse (A) and recipients of WT mock (B), KO mock (C-D), and LV MOI 15- to 25-treated BM (E-F).

and/or promoter activity, $\mathrm{Btk}^{+} \mathrm{T}$ cells were undetectable at all time points.

The progressive increase in $\mathrm{PB}$ B-cell marking reflects the strong selective pressure for $\mathrm{Btk}^{+} \mathrm{B}$ cells in $\mathrm{Btk} / \mathrm{Tec}^{-1-}$ mice. This selective advantage was evident both in the $\mathrm{BM}$ and in peripheral lymphoid compartments in treated animals. For example, in mice treated with MOI 15 to 25 , the relative percentage of $\mathrm{Btk}^{+} \mathrm{BM}$ $\mathrm{B}$ cells increased during the pro/pre to immature B-cell transition (Figure 4B). Increased marking was also evident as immature $\mathrm{B}$ cells entered the periphery and matured into splenic transitional (T1/T2) and FM B cells, and was most striking in peritoneal B1 $\mathrm{B}$ cells. Selection for $\mathrm{Btk}^{+} \mathrm{B}$ cells correlated with increased relative cell numbers at each of these sequential developmental checkpoints.

Consistent with these data, we observed an increase in the average number of viral integrations per cell in spleen relative to $\mathrm{BM}$ derived cells. This difference was most prominent at MOI 50 to 100 , where total BM cells had an average of 1.9 plus or minus 0.7 copies compared with 2.5 plus or minus 0.7 copies in splenic B cells (Figure 4C). A significant copy number difference was also observed in splenic B versus non-B-cell populations at all MOIs. Viral copy number was also generally higher in total BM cells compared with splenic non-B cells, most probably because of the presence of recirculating mature $\mathrm{B}$ cells within the BM population. Combined with the analysis of Btk protein expression, these data demonstrate a strong selective advantage for $\mathrm{E} \mu \mathrm{B} 29-\mathrm{Btk}^{+} \mathrm{B}$ cells in $\mathrm{Btk} / \mathrm{Tec}^{-1-}$ mice, highlighting that even relatively low initial marking levels can lead to large numbers of gene-marked $\mathrm{Btk}^{+}$ cells in the periphery. Of note, consistent with multilineage transduction, sustained viral marking was identified in B celldepleted BM cells isolated from all LV-treated mice at the time of death (average, $1.4 \pm 0.4$ copies for MOI 15-25 at weeks 24-26; data not shown).

\section{E $\mu$ B29-Btk restores Btk-dependent B-cell functional responses}

$\mathrm{Btk} / \mathrm{Tec}^{-1-} \mathrm{B}$ cells fail to generate a sustained calcium signal in response to BCR ligation. Thus, calcium signaling was assessed in splenocytes derived from one experimental cohort using anti-IgM versus ionomycin (control) stimulation. Mice treated with MOI 15 to 25 exhibited an improved anti-IgM calcium flux compared with KO mock controls (Figure 5A). The partial (compared with WT mock control), population-based, calcium response in E $\mu$ B29-Btktreated mice mirrored the relative Btk expression in splenic B cells ( $\sim 38.5 \% \mathrm{Btk}^{+}$cells in the animals shown). As anticipated, both
A
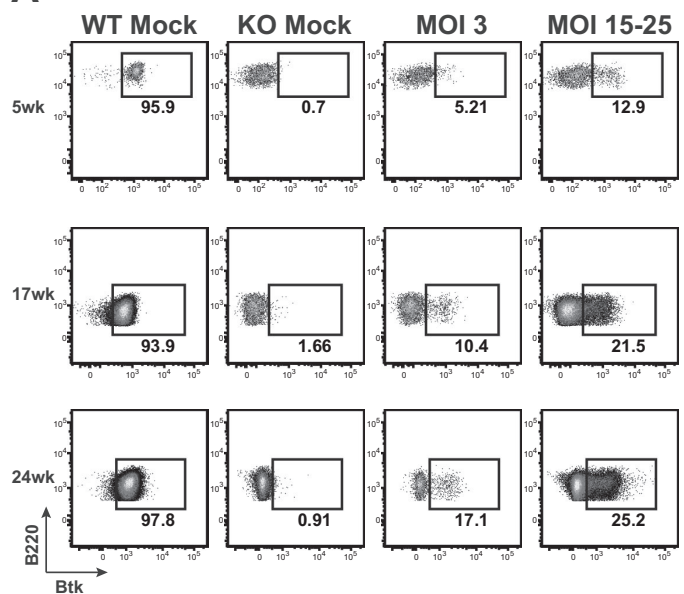

B
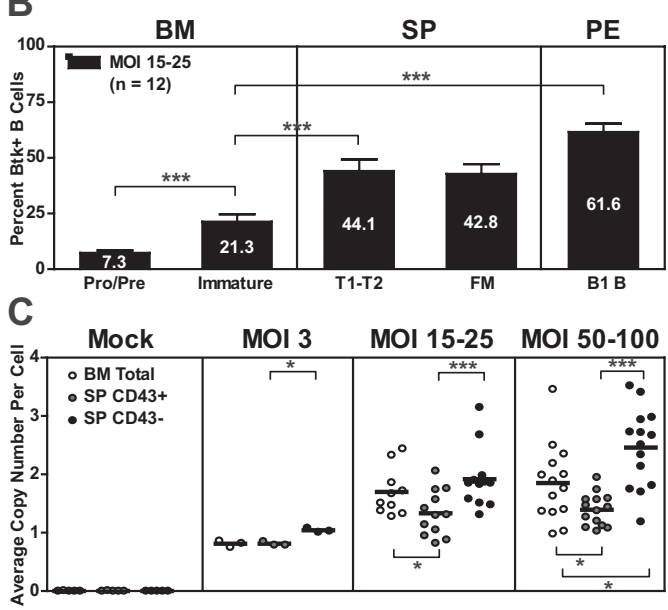

Figure 4. Btk ${ }^{+}$B cells exhibit progressive selective advantage. (A-B) PB, BM, spleen, and peritoneal cells were stained for surface markers and intracellular Btk and analyzed by flow cytometry. (A) Representative data showing Btk expression in PB B cells analyzed at weeks 5, 17, and 24 after transplantation. FACS plots show representative mice from WT mock $(n=7)$, KO mock $(n=8)$, MOI $3(n=3)$, and MOI 15 to $25(n=12)$ experimental groups. (B) Btk ${ }^{+}$cells in various B-cell subsets displayed according to increasing maturity in BM and periphery in MOI 15 to 25 LV-treated mice. (C) gDNA derived from total BM, splenic non-B (CD43 $\left.{ }^{+}\right)$, and $B\left(C D 43^{-}\right)$cell populations was evaluated for viral copy number. Data represent 4 independent experiments. ${ }^{\star \star \star} P<.001 ;{ }^{\star \star} P=.001-.01 ;{ }^{*} P=.01-.05$. 

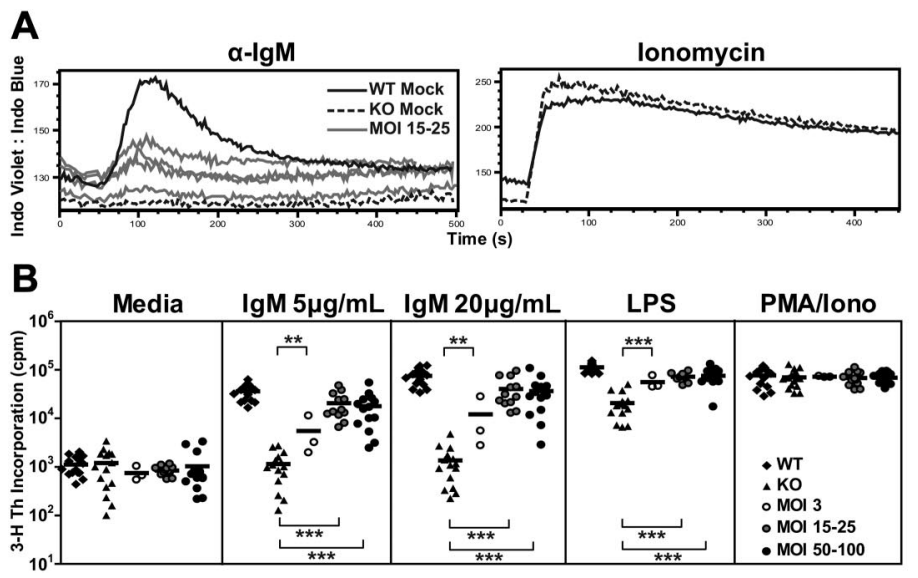

C

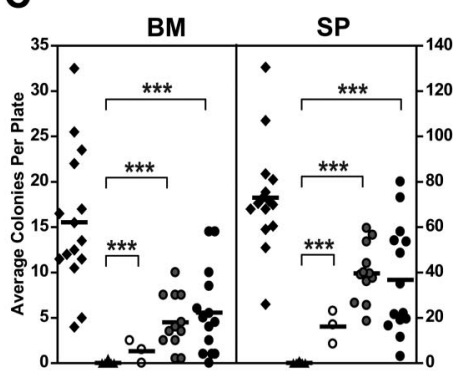

Figure 5. E $\mu$ B29-Btk gene therapy restores Btk-dependent BCR and mitogen signaling. BM and splenocytes cells were assessed using various functional assays at the time of harvest. (A) In 1 of 4 experiments, splenocytes were stained for surface markers, stimulated with anti-lgM or ionomycin, and analyzed for calcium flux. Representative traces from B220+ cells in WT mock $(n=1)$, KO mock $(n=1)$, and MOI 15 to $25(n=4)$ experimental groups are shown. (B) Splenocytes were analyzed for cell proliferation in response to anti-IgM, LPS, or PMA/ionomycin stimulation. (C) BM or splenocytes cells were analyzed for colony-forming unit cell production. WT and KO datasets include both unmanipulated and mock-transplanted animals. Data represent 4 independent experiments, unless otherwise noted. $P$ values compare $\mathrm{E} \mu \mathrm{B} 29$-Btk vs KO groups: ${ }^{* \star \star} P<.001$; ${ }^{\star \star} P=.001-.01 ;{ }^{\star} P=.01-.05$.

WT and KO mock cells responded similarly to ionomycin stimulation.

$\mathrm{Btk} / \mathrm{Tec}^{-1-}$ mice manifest defects in B-cell proliferation in response to either BCR engagement or stimulation with TLR4 ligands (eg, lipopolysaccharide [LPS]). Splenocytes were cultured in media containing anti-IgM, LPS, or phorbol myristate acetate (PMA)-ionomycin and assayed for proliferation using ${ }^{3} \mathrm{H}-$ thymidine incorporation (Figure 5B). Increased proliferation in response to IgM or LPS was observed in all LV-treated animals compared with $\mathrm{KO}$ mock recipients. At $20 \mu \mathrm{g} / \mathrm{mL}$ IgM, MOI 3 showed increased proliferation compared with $\mathrm{KO}$ control $(12099 \pm 13872$ vs $1354 \pm 1193$, respectively). MOI 15 to 25 and MOI 50 to 100 showed much greater increases in proliferation (40185 \pm 27290 and $31074 \pm 18779 \mathrm{cpm}$, respectively), and enhanced responses were also observed using lower-dose anti-IgM or LPS. All populations exhibited similar responses to PMA/ ionomycin, a combined stimulus that bypasses the requirement for Btk in proximal BCR signaling.

To test the ability to proliferate to antigen in association with TLR signals, we cultured BM or spleen cells with sheep red blood cells and LPS in an agar-based, colony-forming assay (Figure 5C). $\mathrm{Btk} / \mathrm{Tec}^{-1-}$ cells failed to respond to these signals (BM, $0.0 \pm 0.1$ colonies; spleen, $0.1 \pm 0.3$ colonies). In contrast, colony formation was observed with both BM (MOI 3, $1.3 \pm 1.3$ colonies; MOI 15-25, $4.5 \pm 3.0$ colonies; MOI 50-100, $4.8 \pm 4.0$ colonies) and splenocytes (MOI 3, $16.2 \pm 7.3$ colonies; MOI 15-25, $39.7 \pm 12.5$ colonies; MOI 50-100, $34.8 \pm 23.8$ colonies) derived from LVtreated mice. The lower colony numbers using BM probably reflect the smaller relative proportion of mature B cells compared with the spleen. Similar to the calcium signal, the partial response of splenic B cells (compared with WT control) in both the colony-forming and ${ }^{3} \mathrm{H}$-thymidine assays correlated with the relative levels of Btk expression in individual $\mathrm{E} \mu \mathrm{B} 29$-Btk-treated mice.

Striking features characteristic of both XLA patients and $\mathrm{Btk} / \mathrm{Tec}^{-1-}$ mice are very low levels of serum immunoglobulin and the inability to mount T-independent antigen responses. Serum levels of IgM in nearly all E $\mu$ B29-Btk-treated mice were markedly increased compared with $\mathrm{KO}$ controls $(\mathrm{KO}, 14.0 \pm 5.7$ relative units; MOI 3, $132.3 \pm 38.3$ relative units; MOI 15-25, $120.1 \pm 88.2$ relative units; MOI 50-100, $115.0 \pm 81.9$ relative units; Figure $6 \mathrm{~A})$. A similar, but smaller, increase was seen for serum $\mathrm{IgG}_{3}$. After immunization with the TI-II immunogen, TNP-Ficoll, the majority of LV-treated mice produced significant levels of TNP-specific IgM (KO, $3.5 \pm 2.0$ relative units; MOI 3, $20.4 \pm 8.8$ relative units; MOI 15-25, $12.7 \pm 8.0$ relative units; MOI 50-100, $7.7 \pm 6.7$ relative units). Similarly, most treated animals also generated significant $\mathrm{IgG}_{3}$ anti-TNP responses (data not shown).

We also tested T-dependent antigen responses using immunization with NP-CGG in alum in a small cohort of mice that were not immunized with TI-II immunogen. LV-treated mice (MOI 10) showed a 6.9-fold increase in NP-specific IgM between day 0 and day 7 compared with 11.8-fold and 3.2-fold increase in WT and $\mathrm{Btk} / \mathrm{Tec}^{-1-}$ mice, respectively (Figure 6B). In addition, LV-treated animals exhibited a 104-fold increase in NP-specific IgG at day 14 ,
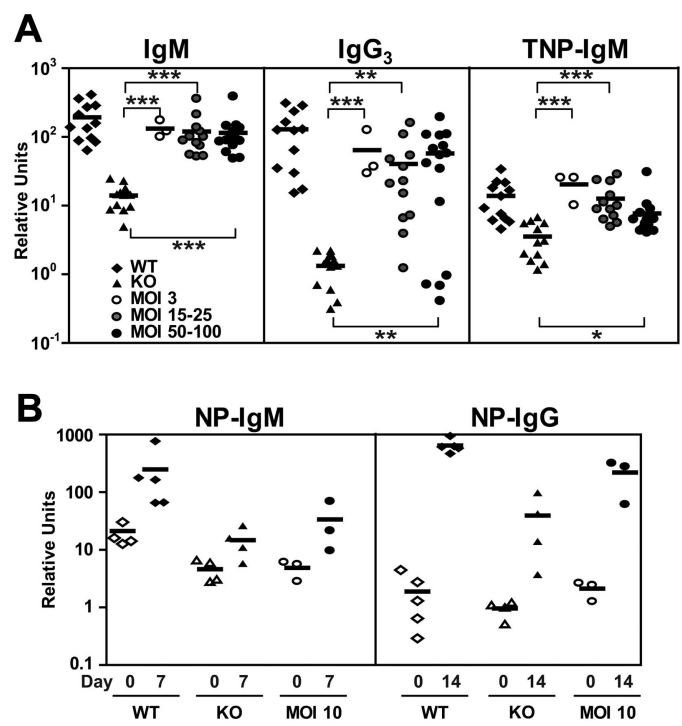

Figure 6. Improved T-independent and T-dependent immune responses in E $\mu$ B29-Btk-LV-treated mice. Mice were immunized with TNP-Ficoll or NP-CGG in alum at 15 to 17 weeks after transplantation. (A) Sera levels of $\operatorname{lgM}, \lg G_{3}$, and TNP-IgM at day 14 after immunization were analyzed by ELISA and expressed relative to $\operatorname{lgM}$ or $\lg \mathrm{G}_{3}$ standard curves. (B) Sera levels of NP-IgM were evaluated by ELISA at days 0 and 7, and levels of NP-IgG were evaluated at days 0 and 14. WT and $\mathrm{KO}$ datasets include both unmanipulated and mock-transplanted animals. Data represent 4 independent experiments $(A)$ and 1 experiment $(B) . P$ values compare E $\mu$ B29-Btk and KO groups: ${ }^{\star \star \star} P<.001 ;{ }^{* \star} P=.001-.01 ;{ }^{\star} P=.01-.05$. 

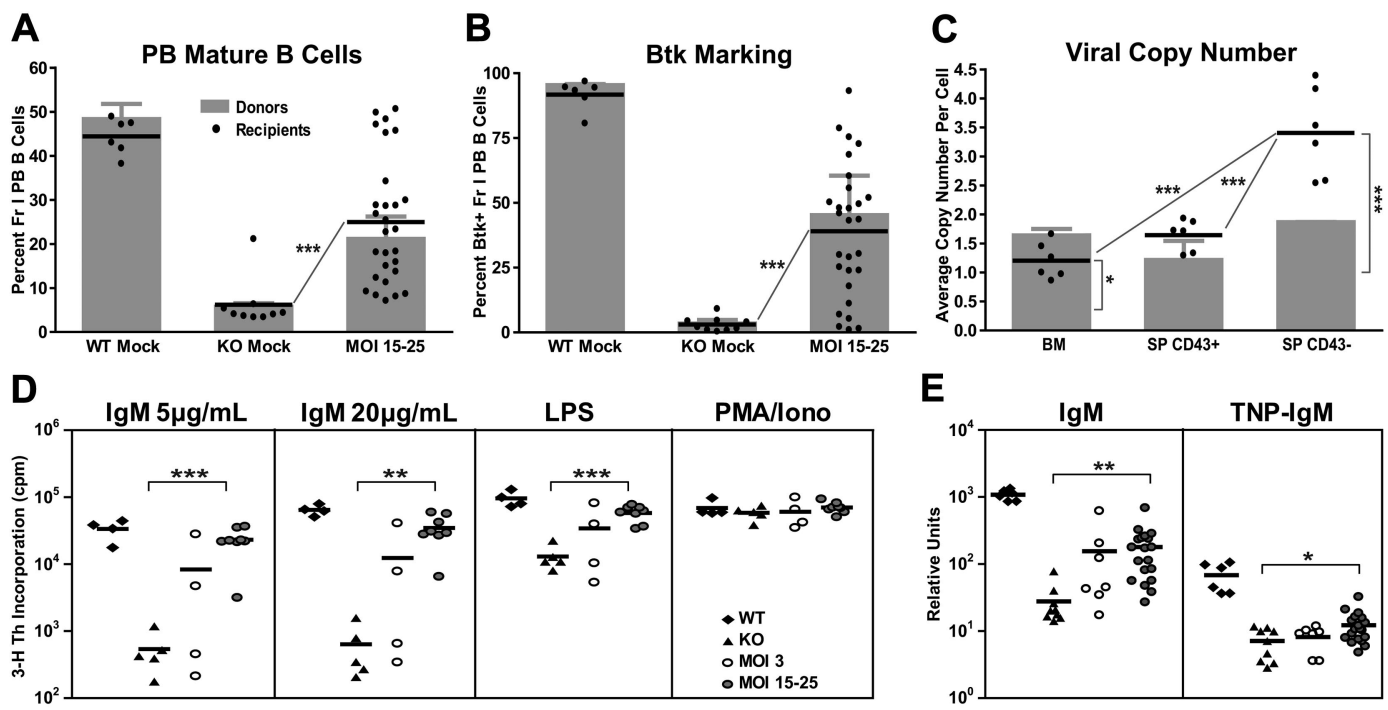

Figure 7. Secondary transplantation reveals sustained marking of Btk/Tec ${ }^{-/-}$hematopoietic stem cells and partial correction of functional deficits. PB, BM, and spleen cells were harvested from secondary recipients at weeks 19 to 27 after transplantation. Cells were subjected to flow cytometric analysis, quantitative PCR copy number determination, and functional assays, as described for primary transplantation experiments. (A) PB cells were analyzed for the percentage of IgMlolgD ${ }^{\text {hi }}$ (Fr I) mature $\mathrm{B}$ cells and compared with primary transplantation donors (shaded bars). (B) PB cells were analyzed for Btk ${ }^{+}$Fr I B cells and compared with donor percentages (shaded bars). (C) gDNA from total BM, splenic non-B $\left(\mathrm{CD}_{4} 3^{+}\right)$, and B $\left(\mathrm{CD} 43^{-}\right)$cell populations was evaluated for viral copy number and compared with donors (shaded bars). (D) Splenocytes were analyzed for cell proliferation in response to anti-IgM, LPS, or PMA/ionomycin stimulation. (E) IgM and TNP-specific IgM were analyzed in immunized mice by ELISA and expressed relative to IgM standard curves. WT and KO datasets include both unmanipulated and mock-transplanted animals, unless otherwise noted. Data

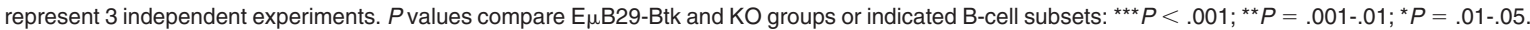

compared with a 342-fold increase for WT and a 41-fold increase for KO animals. Although the numbers of mice tested thus far are still too few to yield statistical significance, these data demonstrate a clear trend toward improved T cell-dependent immune responses in LV-treated mice.

Together, these data demonstrate that $\mathrm{E} \mu \mathrm{B} 29-\mathrm{Btk}$ gene therapy is capable of improving critical B-cell functional responses absent in $\mathrm{Btk} / \mathrm{Tec}^{-1-}$ mice, including proximal and downstream responses to BCR engagement and antibody responses.

\section{Sustained LV-driven Btk expression and activity after secondary transplantation}

We also used secondary bone marrow transplantation to assess the long-term efficacy and potential toxicity of E $\mu$ B29-Btk gene therapy. Cohorts of secondary transplantation recipients were established from each primary experimental group. At 19 to 21 weeks after secondary transplantation, recipients of MOI 15 to 25 treated primary BM had significantly higher percentages of mature Fr I PB B cells compared with $\mathrm{KO}$ mock controls $(24.6 \% \pm 14.4 \%$ vs $6.2 \% \pm 5.7 \%$; Figure $7 \mathrm{~A})$, with an average Btk marking similar to that in the primary donor pool (Figure 7B, compare shaded area with dark bars); however, secondary recipients manifest greater variability. For example, several mice exhibited levels of Fr I and $\mathrm{Btk}^{+}$cells nearly identical to WT controls, reflecting ongoing positive selection for $\mathrm{Btk}^{+} \mathrm{B}$ cells. In contrast, other secondary recipients had much lower levels of $\mathrm{Btk}^{+}$cells, suggestive of LV silencing after HSC expansion in response to serial engraftment.

Similar to primary recipients, we identified an increase in relative viral copy number in spleen versus $\mathrm{BM}$, and splenic $\mathrm{B}$ versus non-B cells in secondary recipients (MOI 15-25, BM, $1.5 \pm 0.7$ copies; splenic B, $3.3 \pm 0.7$ vs non- $\mathrm{B}, 1.8 \pm 0.4$ copies; Figure 7C). Compared with their respective donors, most recipients exhibited similar BM copy number and slightly greater average copy number in splenic B cells, consistent with an ongoing selective advantage for marked B cells. Interestingly, secondary recipients with lower percentages of $\mathrm{Btk}^{+}$Fr I B cells $(7.2 \%, 4.2 \%$, and $17.8 \%$ ) exhibited splenic B-cell marking $(1.5,0.5$, and 2.58 copies, respectively) indistinguishable from animals with highlevel Btk expression, providing additional evidence for silencing or variegation of LV expression in this subset of animals.

Finally, we assessed functional responses in cohorts of secondary recipient mice. Splenocytes were cultured with anti-IgM, LPS, or PMA/ionomycin to measure proliferative capacity. Secondary recipients (MOI 15-25; and MOI 50-100, not shown) demonstrated strong proliferative responses to anti-IgM and LPS (Figure 7D). In addition, mice were immunized with TNP-Ficoll beginning at 17 weeks after transplantation. MOI 15 to 25 and MOI 50 to 100 LV-treated recipients exhibited partial recovery of serum IgM and TNP-specific IgM (Figure 7E; and data not shown). Recipients of MOI 3-treated BM exhibited limited and highly variable functional responses. These data indicate that $\mathrm{E} \mu \mathrm{B} 29$-Btk gene therapy leads to sustained stem cell marking and partial rescue of Btk-dependent developmental and functional responses in the majority of secondary transplanted mice.

\section{Lack of evidence for toxicity in E $\mu$ B29-Btk-treated mice}

We performed an extensive histologic analysis to monitor for potential tissue pathology in $38 \mathrm{E} \mu \mathrm{B} 29-\mathrm{Btk}$-treated or control mice. Nonirradiated WT and KO control animals did not show abnormal features in any examined tissues. In contrast, all animals receiving total body irradiation, including WT and KO mocktreated animals, exhibited moderate to severe lung fibrosis, hemorrhage, and inflammation, as well as limited renal glomerular injury (supplemental Table 1). Instances of focal degeneration of the liver and pancreas were also recorded in both mock and E $\mu$ B29-Btk animals. In addition, analysis of secondary recipients with the highest viral copy numbers did not identify abnormal results compared with mock recipients. Complete blood counts (CBCs) were also performed on 53 secondary transplantation recipients at approximately 24 weeks after transplantation and for 12 unmanipulated controls. We observed no significant differences in platelet, 
monocyte, neutrophil, or T-cell counts in gene-treated versus control animals (supplemental Table 2).

Finally, we evaluated a subset of transplanted mice for viral integration pattern using linear amplification mediated (LAM)PCR. Analysis was performed for primary and secondary recipients, including animals that exhibited the highest levels of Btk marking (supplemental Figure 3). All recipients exhibited evidence for polyclonal marking in splenocytes and purified B cells. One common insertion site was found both in purified B cells and non-B cells derived from the spleen of a primary animal. In addition, another common insertion site was present in both non-B cells from the primary animal and purified B cells of a secondary recipient; both common insertions are consistent with long-term stem cell marking (data not shown). Importantly, although a subset of secondary recipients exhibited an increase in relative Btk marking (and, to a lesser extent, in viral copy number) compared with primary donors, we observed no evidence for clonal dominance in this setting. Consistent with these findings, we have not observed evidence for integration-related leukemic outgrowth in E $\mu$ B29-Btk-treated animals (including 29 primary, 44 secondary, and 20 tertiary recipients followed for at least 20 weeks).

\section{Discussion}

Despite current comprehensive care, studies in genetically defined XLA patients indicate that infectious and noninfectious morbidity remains high, with survival rates as low as $50 \%$ by age $45^{29,30}$ (A. Plebani, Università di Brescia, oral communication at the XIIth Meeting of the European Society for Immunodeficiencies, October $4-7,2006)$. Although prospective studies ${ }^{31-33}$ indicate that the overall prognosis in XLA is improved after earlier recognition and consistent immunoglobulin replacement and antibiotic therapy, these measures remain incompletely protective. Many patients experience chronic mucosal-surface infections and others die of fulminant bacterial infection, neurodegenerative disease, or malignancies. Our studies represent an important first step toward development of B lineage-targeted LV delivery as an alternative therapeutic approach in XLA.

Our combined data provide the first demonstration of successful ex vivo LV gene therapy in an animal model of XLA. Transplantation of E $\mu$ B29-Btk-LV-transduced Lin ${ }^{-}$BM into lethally irradiated recipients led to a reversal of the severe B-cell developmental defects in $\mathrm{Btk} / \mathrm{Tec}^{-1-}$ mice. This therapeutic effect was LV dose-specific, as exposure to LV at MOI 3 led to marking that was insufficient for disease correction. In contrast, animals treated with MOI 15 or greater exhibited significant increases in both percentage and absolute numbers of mature B-cell subsets in the PB, BM, and spleen, with rescue of both early and late Btk-dependent developmental checkpoints. Treated animals also exhibited increased numbers of peritoneal B1 B cells, a critical first line of defense against infections with encapsulated bacteria. In addition to recovery of mature B-cell numbers, LV treatment restored proximal signaling deficits (assessed by calcium flux) and downstream functional responses, including B-cell proliferative and colonyforming responses to antigen- and/or Toll-like-receptor engagement, basal IgM and $\mathrm{IgG}_{3}$ production, and T-independent antigenspecific antibody responses after immunization.

Developmental rescue correlated with a strong selective advantage for virally marked $\mathrm{Btk}^{+} \mathrm{B}$ cells. The overall percentage of $\mathrm{Btk}^{+} \mathrm{B}$ cells increased throughout the following transplantation period, and treated mice also exhibited progressive enrichment for
$\mathrm{Btk}^{+} \mathrm{B}$ cells in developmentally maturing B-cell subsets. Selection for Btk ${ }^{+} \mathrm{B}$ cells was also further enhanced in a subset of secondary transplantation recipients. Consistent with the analysis for Btk protein expression, LV copy number also increased in splenic B versus non-B cells and splenic B versus BM cells, documenting selective advantage in the peripheral B-cell compartment. In contrast, LV marking and Btk expression remained essentially unchanged in non-B cells.

Our data, showing sustained Btk expression, functional responses, and viral integration after secondary transplantation, are consistent with the interpretation that E $\mu$ B29-Btk-LV stably marks long-term HSCs. Further, an extensive analysis in E $\mu$ B29-Btktreated (primary and secondary) transplantation recipients did not identify any detrimental effects (based on histology and CBCs), with the exception of changes resulting from the irradiation conditioning regimen used (present in both LV-treated and control animals). Extended observation of both primary and secondary/ tertiary recipient cohorts also failed to identify evidence for LV integration-related toxicity. Consistent with this, LAM-PCR analysis of LV-treated mice revealed a polyclonal integration profile and no evidence for clonal dominance, even in secondary recipient animals with the highest level of Btk ${ }^{+} \mathrm{B}$ cells. Although we did not identify evidence for systemic autoimmunity based on $\mathrm{CBC}$ or histologic findings, our data cannot rule out the possibility that differences in BCR-mediated signaling in LV-treated mice might promote altered B-cell tolerance. Additional studies will be required to fully address this potential outcome.

These combined observations strongly support the further study of LV gene therapy for XLA. Compared with other immunodeficiency disorders where gene therapy is being pursued, XLA also exhibits several unique features. (1) XLA is the most common primary immunodeficiency exhibiting a selective advantage for normal or reconstituted lymphoid cells. Because of this and their longer life expectancy, XLA patients compose a relatively large cohort for clinical testing. (2) Circulating immunoglobulin has no effect on the selective advantage of $\mathrm{Btk}^{+} \mathrm{B}$ cells. Thus, in contrast to disorders, such as adenosine deaminase-deficient SCID, Btk gene therapy can be pursued without discontinuing definitive supportive care. (3) Unlike T-cell immune deficiency disorders where thymic atrophy may limit lymphoid reconstitution in older persons, B lineage reconstitution (based on autologous transplantation data) remains efficient across a broad age range. (4) Overexpression of $\mathrm{WT}^{34}$ or activated $\mathrm{Btk}^{35}$ does not lead to any observable risk in animals, and Btk functions as a tumor suppressor, limiting the risk for pre-B-cell leukemia. ${ }^{36,37}$ In addition, there is no evidence that mutant Btk can function in a dominant negative fashion, implying that all XLA genotypes will be feasible treatment candidates. (5) The more stable condition of XLA patients (compared with SCID, for example) may permit progressive optimization, or perhaps repetitive delivery, of genetic therapies. (6) The chronic nature of XLA and high cost of long-term administration of intravenous immunoglobulin (currently estimated at $\sim \$ 75000 /$ year) suggest that gene therapy may provide a cost-effective alternative. (7) Finally, the milder disease phenotype in patients with partial Btk activity suggests that even limited restoration of enzymatic activity may provide clinical benefit. ${ }^{38,39}$

Several observations, however, merit additional attention before proceeding toward clinical application in XLA:

First, although highly significant, numerical and functional B-cell reconstitution in E $\mu$ B29-Btk-treated mice was incomplete. Previous studies using transgenic animals indicate that Btk expression differentially impacts key developmental versus functional 
outputs, and endogenous levels of Btk are probably required for full functional correction. ${ }^{40,41}$ Interestingly, although in vitro proliferative responses in gene-treated mice were less than WT controls, such responses were essentially normal when adjusted for the relative percentage of $\mathrm{Btk}^{+}$input cells. Increasing the MOI to more than 25 did not further improve functional recovery, and we observed evidence suggestive of promoter silencing in some secondary recipients. Together, these findings suggest that E $\mu$ B29Btk-LV is subject to variegation of expression in vivo, as also evident for other $\mathrm{LV},{ }^{42}$ and that this may progressively impact expression in differentiating B cells. Additional work is required to determine whether incorporation of alternative elements, for example, the endogenous Btk promoter ${ }^{43-46}$ and/or a ubiquitously acting chromatin opening element, ${ }^{42}$ may limit such variegation and enhance functional recovery.

Second, the conditioning regimen used in our studies is associated with significant toxicity and would not be appropriate for future clinical trials. Of note, sustained donor B-cell engraftment is not achieved in the majority of $\mathrm{B}^{+}$SCID patients (nor in the small number of XLA patients studied) after BM transplantation in the absence of conditioning ${ }^{47,48}$; and host pro-B cells directly limit $\mathrm{B}$-cell reconstitution in nonconditioned, $\operatorname{Rag} 2^{-/-}$or $\mu \mathrm{MT}$ recipient mice. ${ }^{49} \mathrm{Btk}^{\text {null }}$ pro-B cells are similarly predicted to compete with gene-corrected donor cells in our XLA model. Therefore, Btk LV delivery will probably require at least limited marrow cytoreduction. Thus, it will be essential to determine whether nonmyeloabla- tive conditioning (with busulfan or a related regimen) will permit engraftment and Btk marking at levels sufficient for functional rescue in XLA animal models.

\section{Acknowledgments}

The authors thank Jit Khim for excellent technical assistance with murine transplantation studies, Michael Harkey for assistance with LAM-PCR analysis, and Angel Hui for manuscript preparation.

This work was supported by the National Institutes of Health (RO1 awards CA081140 and HL075453; D.J.R.).

\section{Authorship}

Contribution: H.M.K., B.Y.R., B.V.S., B.D.S., and D.L. performed experiments and analyzed the results; H.M.K. generated the figures; B.Y.R. directed lentivirus production; A.A. and S.H.-B. provided additional significant technical and intellectual contributions; and H.M.K. and D.J.R. designed the research and wrote the paper.

Conflict-of-interest disclosure: The authors declare no competing financial interests.

Correspondence: David J. Rawlings, Center for Immunity and Immunotherapies, Seattle Children's Research Institute, 1900 Ninth Ave, Seattle, WA 98101; e-mail: drawling@u.washington.edu.

\section{References}

1. Rawlings DJ, Witte ON. Bruton's tyrosine kinase is a key regulator in B-cell development. Immunol Rev. 1994;138:105-119.

2. Rawlings DJ, Witte ON. The Btk subfamily of cytoplasmic tyrosine kinases: structure, regulation and function. Semin Immunol. 1995;7(4):237246.

3. Tsukada S, Saffran DC, Rawlings DJ, et al. Deficient expression of a B cell cytoplasmic tyrosine kinase in human $\mathrm{X}$-linked agammaglobulinemia. Cell. 1993;72(2):279-290.

4. Conley ME, Brown P, Pickard AR, et al. Expression of the gene defect in $\mathrm{X}$-linked agammaglobulinemia. N Engl J Med. 1986;315(9):564-567.

5. Hendriks RW, de Bruijn MF, Maas A, Dingjan GM, Karis A, Grosveld F. Inactivation of Btk by insertion of lacZ reveals defects in B cell development only past the pre-B cell stage. EMBO J.1996; 15(18):4862-4872.

6. Quintans J, McKearn JP, Kaplan D. B cell heterogeneity: I. A study of B cell subpopulations involved in the reconstitution of an X-linked immune defect of B cell differentiation. J Immunol. 1979;122(5):1750-1756

7. Quan ZS, Dick RF, Regueiro B, Quintans J. B cell heterogeneity: II. Transplantation resistance in xid mice which affects the ontogeny of B cell subpopulations. Eur J Immunol. 1981;11(8):643-649.

8. Rohrer J, Conley ME. Correction of X-linked immunodeficient mice by competitive reconstitution with limiting numbers of normal bone marrow cells. Blood. 1999;94(10):3358-3365

9. Yu PW, Tabuchi RS, Kato RM, et al. Sustained correction of B-cell development and function in a murine model of $X$-linked agammaglobulinemia $(\mathrm{XLA})$ using retroviral-mediated gene transfer. Blood. 2004;104(5):1281-1290.

10. Santilli G, Thornhill SI, Kinnon C, Thrasher AJ. Gene therapy of inherited immunodeficiencies. Expert Opin Biol Ther. 2008;8(4):397-407.

11. Cavazzana-Calvo M, Fischer A. Gene therapy for severe combined immunodeficiency: are we there yet? J Clin Invest. 2007;117(6):1456-1465.
12. Hacein-Bey-Abina S, von Kalle $C$, Schmidt M, et al. A serious adverse event after successful gene therapy for X-linked severe combined immunodeficiency. N Engl J Med. 2003;348(3):255-256.

13. Ott MG, Schmidt M, Schwarzwaelder K, et al Correction of X-linked chronic granulomatous disease by gene therapy, augmented by insertional activation of MDS1-EVI1, PRDM16 or SETBP1. Nat Med. 2006;12(4):401-409.

14. Naldini L, Verma IM. Lentiviral vectors. Adv Virus Res. 2000;55:599-609.

15. VandenDriessche T, Naldini L, Collen D, Chuah MK. Oncoretroviral and lentiviral vector-mediated gene therapy. Methods Enzymol. 2002;346:573589

16. Modlich U, Navarro S, Zychlinski D, et al. Insertional transformation of hematopoietic cells by self-inactivating lentiviral and gammaretroviral vectors. Mol Ther. 2009;17(11):1919-1928.

17. Wu X, Li Y, Crise B, Burgess SM. Transcription start regions in the human genome are favored targets for MLV integration. Science. 2003; 300(5626):1749-1751.

18. Schroder AR, Shinn P, Chen H, Berry C, Ecker JR, Bushman F. HIV-1 integration in the human genome favors active genes and local hotspots Cell. 2002;110(4):521-529.

19. Banerji J, Olson L, Schaffner W. A lymphocytespecific cellular enhancer is located downstream of the joining region in immunoglobulin heavy chain genes. Cell. 1983;33(3):729-740.

20. Cockerill PN, Garrard WT. Chromosomal loop anchorage of the kappa immunoglobulin gene occurs next to the enhancer in a region containing topoisomerase II sites. Cell. 1986;44(2):273282

21. Thompson AA, Wood WJ Jr, Gilly MJ, Damore MA, Omori SA, Wall R. The promoter and 5' flanking sequences controlling human B29 gene expression. Blood. 1996;87(2):666-673.

22. Dull T, Zufferey R, Kelly M, et al. A third-generation lentivirus vector with a conditional packaging system J Virol. 1998;72(11):8463-8471.
23. Ellmeier W, Jung S, Sunshine MJ, et al. Severe B cell deficiency in mice lacking the tec kinase family members Tec and Btk. J Exp Med. 2000; 192(11):1611-1624.

24. Andrews SF, Rawlings DJ. Transitional B cells exhibit a B cell receptor-specific nuclear defect in gene transcription. J Immunol. 2009;182(5):28682878.

25. Takata M, Kurosaki T. A role for Bruton's tyrosine kinase in B cell antigen receptor-mediated activation of phospholipase C-gamma 2. J Exp Med. 1996;184(1):31-40.

26. Scharenberg AM, Humphries LA, Rawlings DJ. Calcium signalling and cell-fate choice in B cells. Nat Rev Immunol. 2007;7(10):778-789.

27. Fluckiger AC, Li Z, Kato RM, et al. Btk/Tec kinases regulate sustained increases in intracellular $\mathrm{Ca} 2+$ following $\mathrm{B}$-cell receptor activation. EMBO J. 1998;17(7):1973-1985.

28. Montecino-Rodriguez E, Dorshkind K. New perspectives in B-1 B cell development and function. Trends Immunol. 2006;27(9):428-433.

29. Plebani A, Soresina A, Rondelli R, et al. Clinical, immunological, and molecular analysis in a large cohort of patients with X-linked agammaglobulinemia: an Italian multicenter study. Clin Immunol. 2002;104(3):221-230.

30. Van der Hilst JC, Smits BW, van der Meer JW. Hypogammaglobulinaemia: cumulative experience in 49 patients in a tertiary care institution. Neth J Med. 2002;60(3):140-147.

31. Howard V, Greene JM, Pahwa S, et al. The health status and quality of life of adults with X-linked agammaglobulinemia. Clin Immunol. 2006;118(2): 201-208.

32. Winkelstein JA, Marino MC, Lederman $\mathrm{HM}$, et al $X$-linked agammaglobulinemia: report on a United States registry of 201 patients. Medicine (Baltimore). 2006;85(4):193-202.

33. Winkelstein JA, Conley ME, James C, Howard V Boyle J. Adults with $\mathrm{X}$-linked agammaglobulinemia: impact of disease on daily lives, quality of 
From bloodjournal.hematologylibrary.org by FREDERIC BARON on January 26, 2012. For personal use only.

life, educational and socioeconomic status, knowledge of inheritance, and reproductive attitudes. Medicine (Baltimore). 2008;87(5):253-258.

34. Drabek D, Raguz S, De Wit TP, et al. Correction of the X-linked immunodeficiency phenotype by transgenic expression of human Bruton tyrosine kinase under the control of the class II major histocompatibility complex Ea locus control region. Proc Natl Acad Sci U S A. 1997;94(2):610-615.

35. Maas A, Dingjan GM, Grosveld F, Hendriks RW. Early arrest in B cell development in transgenic mice that express the E41K Bruton's tyrosine kinase mutant under the control of the CD19 promoter region. J Immunol. 1999;162(11):65266533.

36. Kersseboom R, Middendorp S, Dingjan GM, et al. Bruton's tyrosine kinase cooperates with the B cell linker protein SLP-65 as a tumor suppressor in Pre-B cells. J Exp Med. 2003;198(1):91-98.

37. Feldhahn N, Rio P, Soh BN, et al. Deficiency of Bruton's tyrosine kinase in B cell precursor leukemia cells. Proc Natl Acad Sci U S A. 2005; 102(37):13266-13271.

38. Saffran DC, Parolini O, Fitch-Hilgenberg ME, et al. Brief report: a point mutation in the $\mathrm{SH} 2$ domain of Bruton's tyrosine kinase in atypical X- linked agammaglobulinemia. N Engl J Med. 1994; 330(21):1488-1491.

39. Kornfeld SJ, Haire RN, Strong SJ, et al. A nove mutation (Cys145--> Stop) in Bruton's tyrosine kinase is associated with newly diagnosed $X$-linked agammaglobulinemia in a 51-year-old male. Mol Med. 1996;2(5):619-623.

40. Satterthwaite $A B$, Cheroutre $H$, Khan WN, Sideras $P$, Witte ON. Btk dosage determines sensitivity to $B$ cell antigen receptor cross-linking. Proc Natl Acad Sci U S A. 1997;94(24):1315213157.

41. Pinschewer DD, Ochsenbein AF, Satterthwaite AB, Witte ON, Hengartner H, Zinkernagel RM. A Btk transgene restores the antiviral TI-2 antibody responses of xid mice in a dose-dependent fashion. Eur J Immunol. 1999;29(9):2981-2987.

42. Zhang F, Thornhill SI, Howe SJ, et al. Lentiviral vectors containing an enhancer-less ubiquitously acting chromatin opening element (UCOE) provide highly reproducible and stable transgene expression in hematopoietic cells. Blood. 2007; 110(5):1448-1457.

43. Himmelmann A, Thevenin C, Harrison K, Kehrl $\mathrm{JH}$. Analysis of the Bruton's tyrosine kinase gene promoter reveals critical PU.1 and SP1 sites. Blood. 1996;87(3):1036-1044

44. Rohrer J, Conley ME. Transcriptional regulatory elements within the first intron of Bruton's tyrosine kinase. Blood. 1998;91(1):214-221.

45. Jo EK, Kanegane H, Nonoyama S, et al. Characterization of mutations, including a novel regulatory defect in the first intron, in Bruton's tyrosine kinase gene from seven Korean X-linked agammaglobulinemia families. J Immunol. 2001; 167(7):4038-4045.

46. Yu L, Mohamed AJ, Simonson OE, et al. Proteasomedependent autoregulation of Bruton tyrosine kinase (Btk) promoter via NF-kappaB. Blood. 2008;111(9): 4617-4626.

47. Buckley RH, Schiff SE, Schiff RI, et al. Hematopoietic stem-cell transplantation for the treatment of severe combined immunodeficiency. $N$ Engl J Med. 1999;340(7):508-516.

48. Haddad E, Le Deist F, Aucouturier P, et al. Longterm chimerism and B-cell function after bone marrow transplantation in patients with severe combined immunodeficiency with B cells: a single-center study of 22 patients. Blood. 1999; 94(8):2923-2930.

49. Liu A, Vosshenrich CA, Lagresle-Peyrou C, et al. Competition within the early B-cell compartment conditions B-cell reconstitution after hematopoietic stem cell transplantation in nonirradiated recipients. Blood. 2006;108(4):1123-1128. 